\title{
Dual Band Microstrip Patch Antenna with I \& T Shaped Slots on the Ground Plane
}

\author{
Ajay Kumar Dwivedi \\ M.Tech Scholar \\ Department of Electronics \\ \& Communication \\ SSET, SHIATS, \\ Allahabad
}

\author{
Rajeev Paulus \\ Professor \\ Department of Electronics \\ \& Communication \\ SSET, SHIATS, \\ Allahabad
}

\author{
A.K Jaiswal \\ Professor \& Head \\ Department of Electronics \\ \& Communication \\ SSET, SHIATS, \\ Allahabad
}

\author{
Aditi Agrawal \\ Assistant Professor \\ Department of Electronics \\ \& Communication \\ SSET, SHIATS, \\ Allahabad
}

\begin{abstract}
A new dual band microstrip patch antenna with I \& T slots on the ground plane has been designed. Observation has been made for the two resonant frequencies in $2.23-2.37 \mathrm{GHz}$ and 4.60-4.76 GHz bands with improved impedance bandwidth in comparison to that of reference patch antenna. The proposed antenna can suitably be used in field of WLAN and C-band application. The proposed antenna has manifested the broader radiation pattern with maximum field strength of approximate $15 \mathrm{~dB}$ at $2.37 \mathrm{GHz}$ and $5 \mathrm{db}$ at $4.7 \mathrm{GHz}$ with better voltage standing wave ratio which indicates minimum reflection and better impedance matching. The simulation is carried out by high frequency structure simulator.
\end{abstract}

\section{Keywords}

Microstrip patch antenna, slotted ground plane, meandering, HFSS, VSWR, Radiation pattern.

\section{INTRODUCTION}

A know- how of meandering an antenna's radiating patch is an effective method to obtain the reduced size of microstrip patch antenna [1-3]. Two slots insertion in the non radiating edges of the antenna patch provide an effective way for the meandering technique. Due to the meandering slots, the length for the excited patch surface current paths has increased, it lowers the antenna resonant frequency and we achieve dual band resonating structure. Many compact microstrip antenna designs such as using shorting pin loading, high permittivity substrate etc have been under study, in the proposed design The impedance bandwidth has increased in comparison to conventional microstrip antennas [5-6]. Modifications in microstrip antenna technology have been taking place since 1970. Basic elements of microstrip antenna and its arrays have been utilized for a period of 35 years approximately at a moderate level [8]. For the design of patch and ground on a dielectric substrate material the conductors- copper and gold due to their better conductivity and adhesive property are mostly used [7]. The fringing fields in the gap of patch edge and the ground plane cause electromagnetic wave radiations from the microstrip patch antenna [9]. Narrow bandwidth has been a major demerit of the microstrip patch antenna [10], for the remedial action of narrow bandwidth demerit, has directed many of the researchers have directed towards other approach such as meandering and some useful U- slots [11]. For dual band and multi band operations a critical analysis has been performed on the U-slot patch antennas [12].

In this paper, we suggest a new compact microstrip antenna along with meandering slots in the ground plane as shown in Figure 1. The proposed patch is resonant at two frequencies which are suitable for WLAN and C band applications [4]. Embedding the I and T slots in the ground plane of the patch antenna has increased the quality factor of the suggested design. The impedance band width and the antenna field pattern both have also been achieved larger than those of the corresponding conventional microstrip patch antenna.

\section{ANTENNA DESIGN}

Figure 1 shows the two dimensional view in $\mathrm{X}$-Y plane of the suggested microstrip patch antenna with I \& $\mathrm{T}$ slots in ground plane. The ground plane and the rectangular radiating patch are made of copper and the dimensions of the substrate material FR-4 and that of the ground have taken $50 \mathrm{~mm} \times 50$ $\mathrm{mm}$ in X-Y plane. The two slots of shapes I and T have been etched out from the ground plane and the coaxial probe feed point at a position $d_{p}=5 \mathrm{~mm}$ from the patch centre along with the $\mathrm{Z}$ axis is set between them.

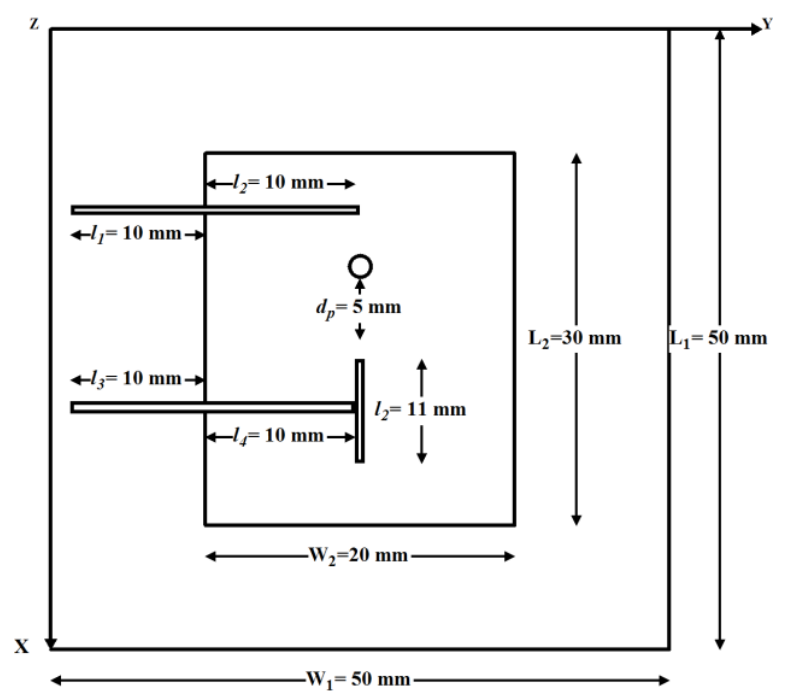

Fig 1: Structure of proposed antenna

The rectangular radiating patch having dimensions of $\quad L=$ $30 \mathrm{~mm}$ and $W=20 \mathrm{~mm}$ is printed on a microwave substrate of thickness $h=1.6 \mathrm{~mm}$ and relative permittivity $\varepsilon_{r}=4.4$ and the etched slots with a narrow width $1 \mathrm{~mm}$. In this study we have length of $l_{1}=10 \mathrm{~mm}$ and $l_{2}=10 \mathrm{~mm}$, where $l_{1}$ and $l_{2}$ being the I-slot length outside and inside the projection image of the radiating patch in the ground plane respectively. For the convenience Table I display dimensions of the antenna. 


\section{RESULT AND DISCUSSION}

The proposed antenna is constructed and analyzed using high frequency structure simulator (HFSS) electromagnetic solver based on finite element method. The field patterns of patch antenna are $15.66 \mathrm{~dB}, 17.55 \mathrm{~dB}$ at $2.32 \mathrm{GHz}$ and $4.7 \mathrm{GHz}$ respectively, return loss of $-17 \mathrm{~dB},-20.44 \mathrm{~dB}$ in the lower band of $2.23-2.37 \mathrm{GHz}$ and the upper band $4.60-4.76 \mathrm{GHz}$ respectively.

The impedance bandwidths at $-10 \mathrm{~dB}$ of the proposed patch antenna have been observed to be $6.03 \%$ and $3.03 \%$ in the lower band and the upper band respectively which are the improved results in comparison to the reference patch without slots.

Table 1. Dimensions of proposed Antenna

\begin{tabular}{|c|c|}
\hline Substrate length $\left(\mathrm{L}_{1}\right)$ & $50 \mathrm{~mm}$ \\
\hline Substrate width $\left(\mathrm{W}_{1}\right)$ & $50 \mathrm{~mm}$ \\
\hline Substrate thickness $(\mathrm{h})$ & $1.6 \mathrm{~mm}$ \\
\hline Patch length $\left(\mathrm{L}_{2}\right)$ & $30 \mathrm{~mm}$ \\
\hline Patch width $\left(\mathrm{W}_{2}\right)$ & $20 \mathrm{~mm}$ \\
\hline I- slot $\left(l_{1}\right)$ & $10 \mathrm{~mm}$ \\
\hline I- slot $\left(l_{2}\right)$ & $10 \mathrm{~mm}$ \\
\hline T- slot $\left(l_{3}\right)$ & $10 \mathrm{~mm}$ \\
\hline T- slot $\left(l_{4}\right)$ & $10 \mathrm{~mm}$ \\
\hline T- slot $\left(l_{5}\right)$ & $11 \mathrm{~mm}$ \\
\hline Slot gap width & $1 \mathrm{~mm}$ \\
\hline
\end{tabular}

The return losses for the proposed antenna and the reference antenna have been shown in Figure 2.

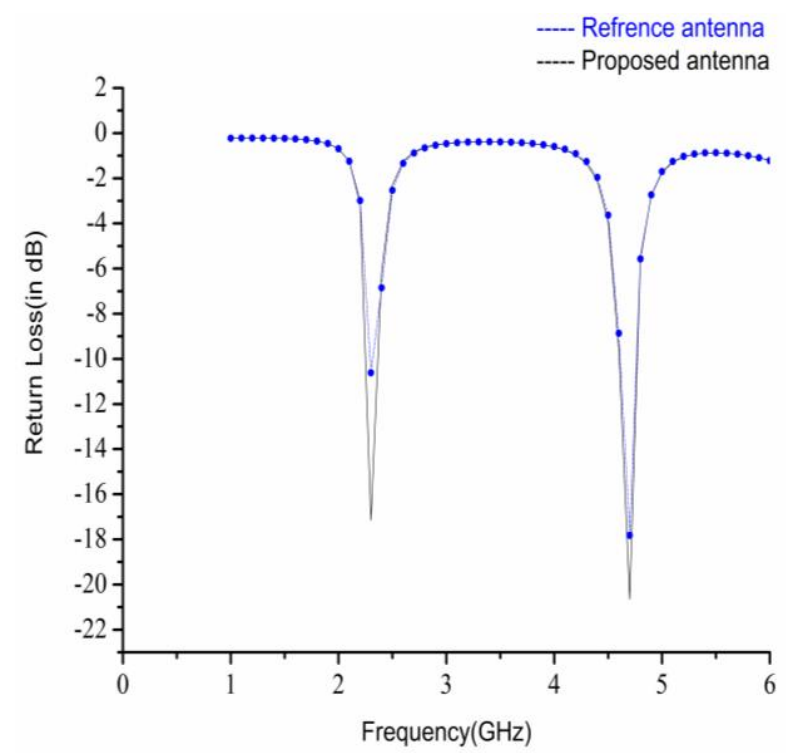

Fig 2: Return loss for reference Antenna and proposed Antenna
The value of VSWR is less than 2 for operating frequencies range. The simulated results for the proposed microstrip patch antenna in terms of radiation pattern, Field pattern (at both central frequency) and voltage standing wave ratio (VSWR< 2) are shown in Figure 4 and Figure 5 respectively. In figure 3 the radiation field pattern for reference patch antenna is shown, at lower frequency proposed patch antenna has no sharp back lobe. The back lobe just beneath the patch radiation pattern in Figure 3 has been eliminated and improved result is shown in Figure 4.

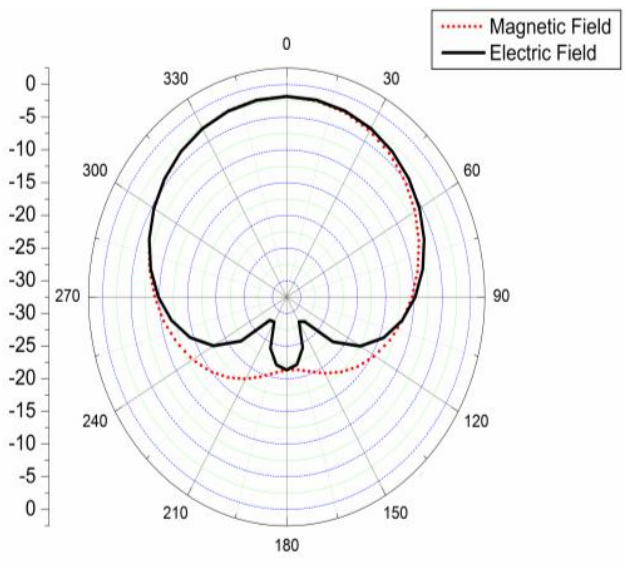

Fig 3: Electric field and magnetic field pattern of reference antenna

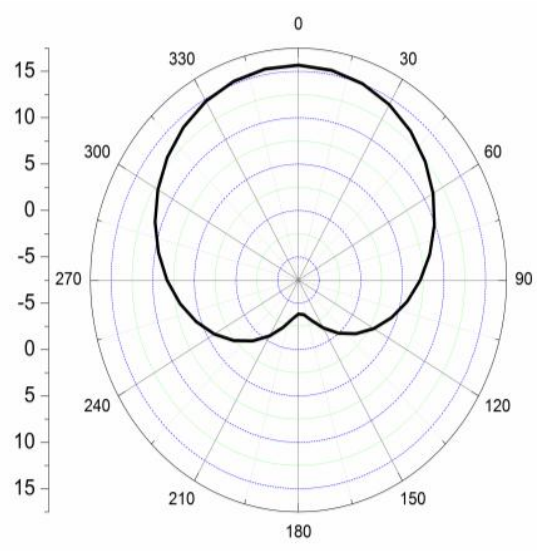

(a)

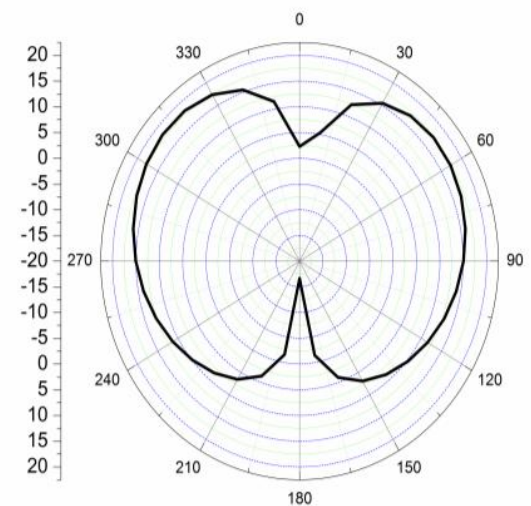

(b)

Fig 4: Field pattern of proposed antenna at (a) $2.32 \mathrm{GHz}$ (b) $4.7 \mathrm{GHz}$ 


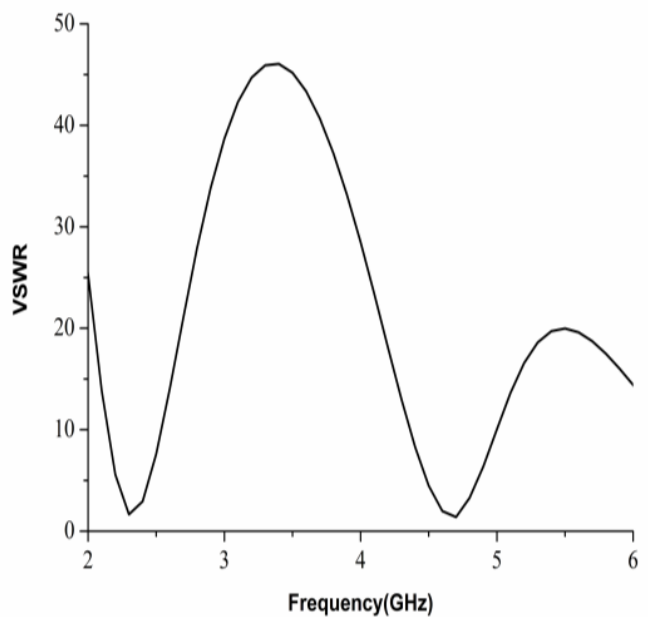

Fig 5: VSWR for proposed patch antenna

The electric field distribution is shown in Figure 6. The maximum electric field distribution attained over the patch at $2.3 \mathrm{GHz}$ is $4.65 \times 10^{3} \mathrm{~V} / \mathrm{m}$ but its expansion tends towards a corner of the plane of the patch. The radiation in broad area of the patch takes place near the probe with average field strength of $2.33 \times 10^{3} \mathrm{~V} / \mathrm{m}$. The field distributed is of less magnitude, it means the near field distribution which is of no significance is achieved to be less but far field distribution is up to the standard.

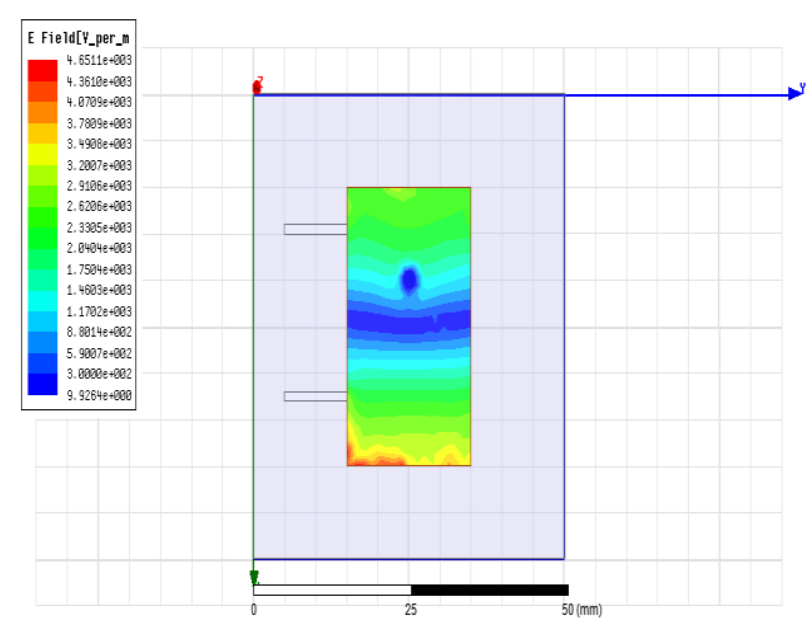

Fig 6: Electric field distribution at $2.37 \mathrm{GHz}$

The probe surrounds with magnetic field of $8.3 \times 10^{2} \mathrm{~A} / \mathrm{m}$ at $2.37 \mathrm{GHz}$. The non radiating edge accompanies with 4.38 $\mathrm{A} / \mathrm{m}$ magnetic field. Most of the middle part of the patch exhibits a radiation from $25 \mathrm{~A} / \mathrm{m}$ to $47 \mathrm{~A} / \mathrm{m}$ over the upper hemisphere of the patch plane. $68.8 \mathrm{~A} / \mathrm{m}$ strength has been observed at the tip of the probe. The magnetic field distribution at $2.37 \mathrm{GHz}$ has been shown in Figure 7.

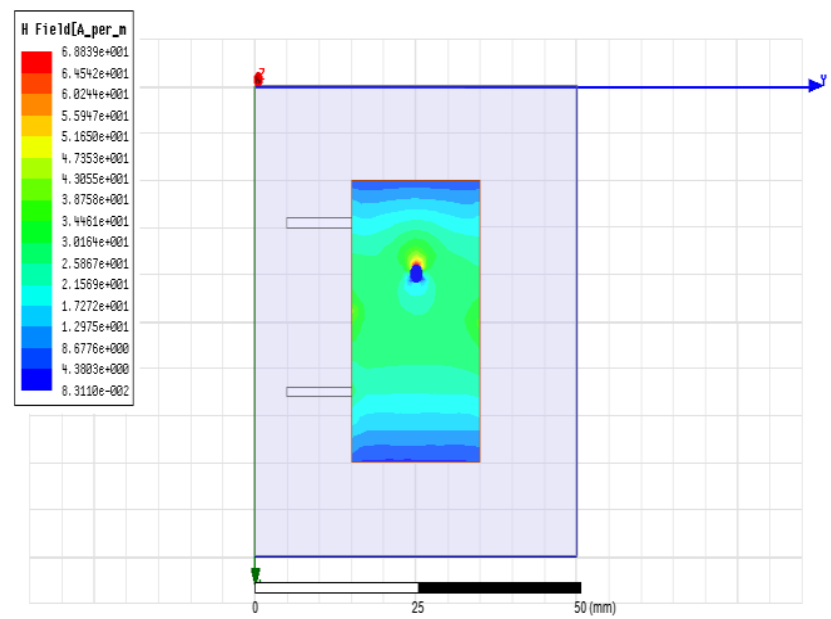

Fig 7: Magnetic field distribution at $2.37 \mathrm{GHz}$

The Electric field distribution at $4.7 \mathrm{GHz}$, near the probe feed position the radiated field propagates in two directions towards the non radiating edge corners with $6.6 \times 10^{2} \mathrm{~V} / \mathrm{m}$ and also spreads along a strip parallel to the non radiating edge with approximate same strength over the I-slot in the ground as shown in Figure 8. The mid area of the slot in the ground has denser distribution with $2.9 \times 10^{3} \mathrm{~V} / \mathrm{m}$ over the patch. The maximum field strength occurs over the radiating edge with $5.2 \times 10^{3} \mathrm{~V} / \mathrm{m}$.

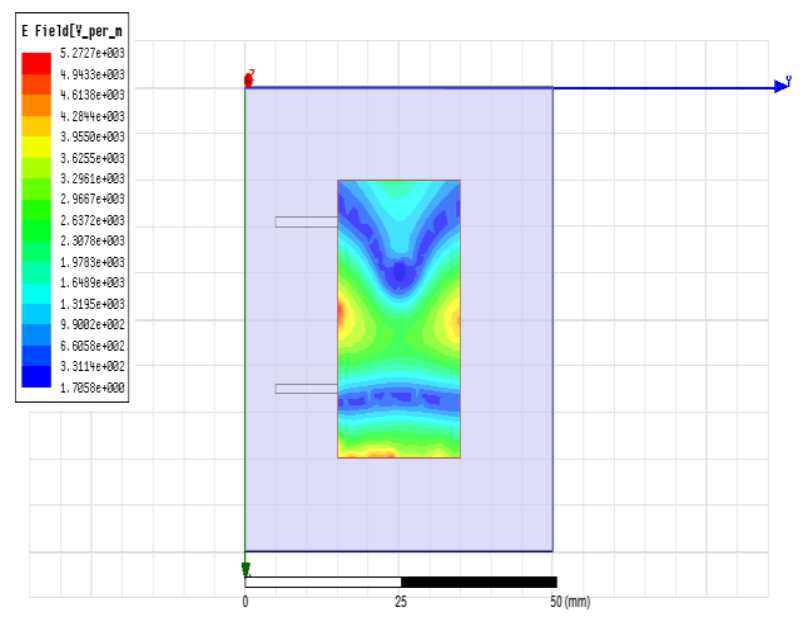

Fig 8: Electric field distribution at $4.7 \mathrm{GHz}$

The magnetic field distribution at 4.7 GHz shown in Figure 9, has the least field strength around the probe and the mid of the patch is also filled with a strip wise magnetic field of 9.85 $\mathrm{A} / \mathrm{m}$ and it increases up to $23.8 \mathrm{~A} / \mathrm{m}$. The magnetic field strength approximates up to $47.13 \mathrm{~A} / \mathrm{m}$ over the large part of the patch. The magnetic field parallel to the non radiating edge is $19.2 \mathrm{~A} / \mathrm{m}$. 


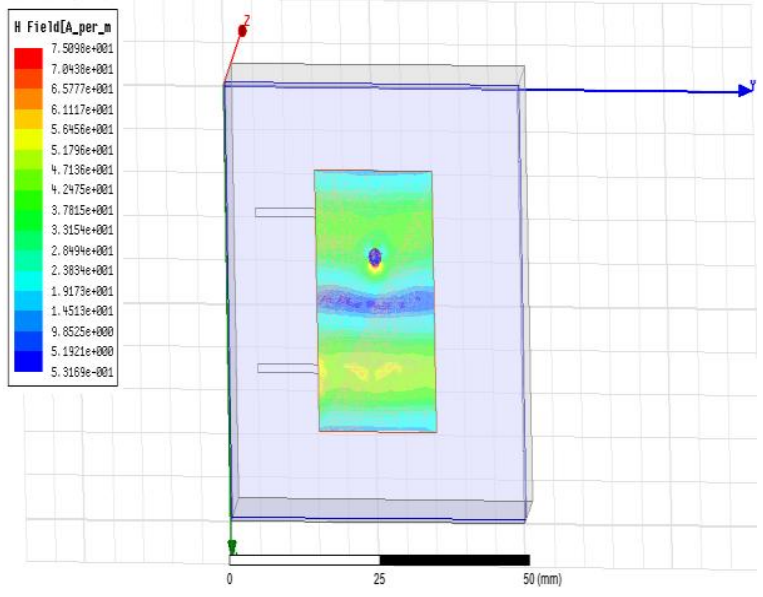

Fig 9: Magnetic field distribution at 4.7 GHz

\section{CONCLUSION}

A novel design of compact microstrip patch antenna with a meandered ground plane has been proposed and analyzed using HFSS. By providing the meandering slots of $\mathrm{I}$ and $\mathrm{T}$ shape on the conductive ground plane, it is observed that the dual band compact resonating structure with minimum value of return loss has been obtained for dual operating frequency ranges. The structure can be suitably used for WLAN and CBand applications. In future the structure is expected to be modified for rectenna with the help of Advanced Design System software.

\section{ACKNOWLEDGEMENT}

This research paper titled "Dual Band Microstrip Patch Antenna with I \& T Shaped Slots on the Ground Plane" is achievable through the help and consistent support from my parents, teachers, friends and all sentient beings. Especially, I acknowledge my gratitude towards the following significant advisors and contributors. Firstly, I would like to thank Prof. Rajeev Paulus for his support and encouragement. I would also like to thank Prof. \& Head A.K. Jaiswal and Asst. Prof. Aditi Agrawal to provide valuable advices. The product of this research paper would not be possible without all of them.

\section{REFERENCES}

[1] K.L. Wong, C.L. Tang, H.T. Chen, "A compact meandered circular microstrip antenna with a shorting pin”, Microwave Opt. Technol. Lett., vol. 15, pp. 147149, 1997.

[2] J.H. Lu and K.L. Wong, "Slot-loaded, meandered rectangular microstrip antenna with compact dual frequency operation", Electron Lett., vol. 34, pp. 10481050,1998

[3] S. dey and R. Mittra, "Compact microstrip patch antenna", Microwave Opt. Technol. Lett., vol. 13, pp. 1214, 1996.

[4] A. Mishra, J.A. Ansari, Km Kamakshi, A. Singh, Mohd. Aneesh, B.R. Vishwakarma, "Compact dual band rectangular microstrip patch antenna for $2.4 / 5.12-\mathrm{GHz}$ wireless applictions,"Wireless Netw., August 2014.

[5] Belhachat Messaouda, Bakir Mohammed, Shouzheng Zhu, Jingao Liu, "Reconfigurable dual band circularly polarized microstrip patch antenna for wireless applications", Journal of Electronics(China), vol. 21, issue 5, pp. 421-425, September 2004.

[6] J.-Y.Jia-Yi Sze and K.-L.Kin-Lu Wong, "Slotted rectangular microstrip antenna for bandwidth enhancement," IEEE Trans. Antennas Propagat., vol. 48, pp. 1149-1152, Aug. 2000.

[7] D.M. Pozara and D.H. Schaubert, "Microstrip antennas, the analysis and design of microstrip antennas and arrays," New York, NY:IEEE Press, 1995.

[8] P. Bhartia, P. Rao, K.V.S and R.S. Tomar, "Millimeter wave microstrip and printed circuit antennas," Norwood, MA: Artech House, 1991.

[9] D.M. Pozara and D.H. Schaubert, "Microstrip antennas, the analysis and design of microstrip antennas and arrays," New York, NY:IEEE Press, 1995.

[10] S.A. Long and M.D. Waton, "A dual-frequency stacked circular disc antenna ," IEEE Transactions on Antennas and Propagation,27, 1979, pp. 281-285.

[11] J.S. Dahele, K.F. Lee and D.P. Wong , "Dual-frequency stacked angular microstrip antenna," IEEE Transactions on Antennas and Propagation, 35, 1987, pp. 1281-1285.

[12] C.A. Balanis, "Antenna Theory Analysis and Design," John Wiley and Sons, 2005. 